\title{
THE SESONAL ACTIVITY OF THE MAIN INSECT PARASITOIDS ATTACKING PUPAL STAGE OF THE CABBAGE BUTTERFLY Pieris rapae L. ON DIFFERENT HOST PLANTS. \\ Awadalla, S. S. ; Hala A. EL-Serafi ${ }^{\star}$; Salwa Abdel - Samad ${ }^{\star \star}$ and Ekram A. Abdou** \\ Economic Entomology Dept. Fac. Agric. Mans. Univ. \\ Biological Control Dept. Sakha Agric. Res. Station Plant Protection Res. Inst. Agric. Res. Center.
}

\begin{abstract}
The experiment was carried out at the experimental farm of the Plant Protection Department Sakha Agriculture Research Station, Kafr El-Sheikh, during three successive vegetable growing seasons, 2011/12and 2012/13 on cabbage (Brassica oleracea var. capitata L.), cauliflower (B. oleracea var. botrytis L.), and Canola rape (Brassica napu. oleifera L ).

Cabbage plants harboured the highest average percentage of the pupal parasitoids Brachymeria femorata parasitoid during three successive seasons 2011 , 2012 and 2013 represented by 17.5 and $18.3 \%$ followed by cauliflower plants 13.9 and $14.9 \%$.While, canola plants recorded the last category and represented by 11.6 and $13.9 \%$,respectively .Moreover, there was a highly significant differences between the percentage of B.femorata parasitoids on different cruciferous plants during the two successive seasons. The cabbage plants harboured the highest average percentage of Pteromalus puparum during the three successive seasons 2011/12 and 2012/13 represented by $30.8 \%$ and $31.5 \%$ followed by cauliflower plants 24.4 and $26.6 \%$ while, canola plants recorded the last category and represented by $19.6 \%$ and $14.7 \%$,respectively .Moreover there were a highly significant differences between the percentage of $P$. puparum on different cruciferous plants during the two successive seasons. Cabbage plants harboured the highest average percentage of Phryxe vulgaris during three successive seasons 2011/12 and 2012/13 and represented by $8.9 \%$ and $8.1 \%$ followed by cauliflower plants 5.8 and $6.8 \%$ while, canola plants recorded the last category and represented by $3.5 \%$ and $2.9 \%$ respectively.Moreover, there were a highly significant differences between the percentage of $P$. vulgaris on different cruciferous plants during the two successive seasons.
\end{abstract}

\section{INTRODUCTION}

The small cabbage white butterfly, Pieris rapae L. (Lepiddoptera: Pieridae) which synonyms with Artogeia rapae (Ibrahim et al., 1996)and considedrd one of the most serious insect pests which infests cruciferous vegetables (Del et al., 2005) and causing considerable damage especially to cabbage and cauliflower was determined by (Jankowska, 2005). Parasitoids play an important role in reducing the population density of $P$. brassicae. Moreover, eggs and larvae are attacked by generalist predators such as spiders,chrysopids, staphylinids and carabids (Pfiffner et al .2009) .Feeding injury caused by this caterpillar may reduce production to zero (Abdel-Razek 
et al., 2006). The pupal parasitoid, Pteromalus puparum ( Hymenoptera : Pteromalidae ) was the most important parasitoid as being "accidentallyintroduced" in the late 1800s, presumably after the invasion by $P$. rapae in 1860 . The activity of that parasitoid was recorded by many authors (Barron, 2007). Brachymeria femorata (Hymenoptera: Chalcididae), the $2^{\text {nd }}$ pupal parasitoid of $P$. rapae was recorded by (Abbas , 1985 ) and Patriche, 2004) . In addition, the tachinid, Phryxe vulgaris was recorded against $P$. rapae pupa (Uzun, 1987 and Patriche, 2004). Other pupal parasitoids were recorded, i.e. the ichneumonid Pimpla instigator (Uzun, 1987), and Compsilura concinnata (Patriche, 2004).

The aim of this study was to study seasonal activity of the main insect parasitoids attacking pupal stage of the cabbage butterfly $P$. rapae on different host plants.

\section{MATERIALS AND METHODS}

The experiment was carried out at the experimental farm of the Plant Protection Department Sakha Agriculture Research Station, Kafr El-Sheikh, during two successive vegetable growing seasons, 2011/12and 2012/13 on cabbage (Brassica oleracea var. capitata L.), cauliflower (B. oleracea var. botrytis L.), and Canola rape (Brassica napus oleifera L.).

Three field crops, cabbage, cauliflower and Canola were examined to detect seasonal activity of the main insect parasitoids attacking pupal stage of the cabbage butterfly $P$. rapae on different host plants. i.e. , the pupal parasitoid Pteromalus puparum L. , (Pteromalidae); Brachymeria femorata Panzer, (Chalcididae) and Phryxe vulgaris Fallen, (Tachinidae). Two successive seasons were examined for each crops, cabbage, cauliflower and Canola during seasons2011/ 12 and 2012/13 with growing period from September to December and May to August and January to April .P. rapae pupa were counted weekly in the field during the two tested seasons .Samples were taken randomly from cardinal directions of area about one Fadden divided for three crops for each host plant. Pupae of $P$. rapae counted weekly/50 plants/crop. These pupae were transferred to the laboratory and kept under laboratory conditions in Petri dishes. The emergency of butterflies or any parasitoid adults were counted and the percentage of parasitoids were done.

\section{Statistical analysis :}

Data were statistically analyzed by one-way ANOVA, using the general linear model procedure (SAS, 1986). Test of significance for differences among treatments were done according to Duncan (1955).

\section{RESULTS AND DISCUSSION}

Data in Table (1) showed that the percentage of the parasitoids $B$. femorata Panzer were recorded in the first seasons 2011/12.The results 
indicated that the first appearance of solitary parasitoid, B. femorata on cabbage plants was recorded in September with(16.7\%). The highest average percentage of $B$. femorata recorded on cabbage (36.2\%) in October and on cauliflower $(27.6 \%)$ in December and on canola $(25 \%)$ in November and December while the lowest percentage of parasitism recorded on cabbage (12\%)in February and (11.1\%)on cauliflower in September and followed by canola $(4.5 \%)$ in October.

The obtained data in Table(1)showed that ,the highest average percentage of B.femorata during the second seasons 2012/13 recorded (44.4\%) on cabbage at April and followed by (39.6\%)on cauliflower plants at October and $(28.3 \%)$ on Canola plants at November .Meanwhile, the lowest average percentage were recorded in July (13.6\%) on Cabbage plants and (12.5\%) on cauliflower at September and on canola represented by $(10.0 \%)$ and the parasitoids disappeared during January in three crops.

As conclusion, data in Table (1) revealed that, cabbage plants harboured the highest average percentage of the pupal parasitoids $B$. femorata parasitoid during the two successive seasons 2011, 2012 and 2013 represented by 17.5 and $18.3 \%$ followed by cauliflower plants 13.9 and 14.9 $\%$. While , canola plants recorded the last category and represented by 11.6 and $13.9 \%$,respectively .Moreover there were a highly significant differences between the percentage of B.femorata parasitoids on different cruciferous plants during the two successive seasons .

Table (1) The seasonal activity of of the parasitoid Brachimerya femorata parasitized pupae on different cruciferous crops during seasons 2011/12 and 2012/13.

\begin{tabular}{|l|c|c|c|c|c|c|}
\hline \multirow{2}{*}{ Months } & \multicolumn{3}{|c|}{ 2011/2012 } & \multicolumn{3}{c|}{ 2012 / 2013 } \\
\cline { 2 - 7 } & Cabbage & Cauliflower & Canola & Cabbage & Cauliflower & Canola \\
\hline Sep & 16.7 & 11.1 & 0.0 & 24.1 & 12.5 & 0.0 \\
\hline Oct. & 36.2 & 25.2 & 4.5 & 44.4 & 39.6 & 23.75 \\
\hline Nov. & 23.4 & 21.1 & 25 & 23.4 & 21.2 & 28.6 \\
\hline Dec. & 25.3 & 27.6 & 24.9 & 23.6 & 21.2 & 28.3 \\
\hline Jan. & 0.0 & 0.0 & 25 & 0.0 & 0.0 & 0.0 \\
\hline Feb. & 12 & 16.7 & 20 & 0.0 & 0.0 & 12.5 \\
\hline Mar. & 30 & 25 & 17.6 & 0.0 & 0.0 & 12.5 \\
\hline Apr. & 21.4 & 18.2 & 0.0 & 14.4 & 11.3 & 9.2 \\
\hline May & 27 & 22.9 & 20.0 & 23.5 & 21.0 & 0.0 \\
\hline Jun. & 23.3 & 20.3 & 17.5 & 24.4 & 22.2 & 10.0 \\
\hline Jul. & 24.7 & 20.8 & 15.0 & 13.6 & 15.4 & 20.0 \\
\hline Aug. & 25 & 15 & 0.0 & 26.3 & 0.0 & 0.0 \\
\hline Mean \pm SE & $17.5 \pm 0.29^{\mathrm{a}}$ & $13.9 \pm 0.35^{\mathrm{b}}$ & $11.6 \pm 0.58^{\mathrm{c}}$ & $18.3 \pm 0.38^{\mathrm{a}}$ & $14.9 \pm 0.57^{\mathrm{b}}$ & $13.9 \pm 0.23^{\mathrm{c}}$ \\
\hline
\end{tabular}

Data in Table (2)showed that gregarious parasitoid, $P$. puparum was observed in the field parasitizing $P$. rapae pupae and recorded for the first time in September plantation and after three weeks from survey recorded the highest percentage(54.1\%) during November Data arranged in Table(2) showed the highest average of monthly number of parasitoids P.puparum during the first season 2011/2012was found on cabbage(54.1\%)and followed by cauliflower(42.1\%)on November. and on Canola(35\%)in November 
2011 , while the lowest average percentage of parasitoids were recorded in September and represented5.5\%in September on cabbage 20\%in March on Cauliflower and 14\%in February on Canola plants, respectively

The obtained data in Table (2) showed that. The highest average percentage of $P$. puparum in the second seasons 2012/13 recorded in November and represented by $52.5 \%$ on cabbage and followed by $43.3 \%$ in June on cauliflower and $28 \%$ in April on canola plants, respectively . Meanwhile, the lowest average the percentages were recorded in September and represented by $10.3 \%$ on cabbage and $23.3 \%$ in December on cauliflower and $13 \%$ in June on canola plants respectively.

As conclusion, data in Table (2) revealed that, The cabbage plants harboured the highest average percentage of P.puparum during the three successive seasons $2011 / 12$ and $2012 / 13$ represented by $30.8 \%$ and $31.5 \%$ followed by cauliflower plants 24.4 and $26.6 \%$ while, canola plants recorded the last category and represented by $19.6 \%$ and $14.7 \%$,respectively .Moreover, there were a highly significant differences between the percentage of $P$. puparum on different cruciferous plants during the two successive seasons.

Table(2)The seasonal activity of the parasitoid Pteromalus puparum parasitized pupae on different cruciferous crops during seasons 2011/12 and 2012/13.

\begin{tabular}{|l|c|c|c|c|c|c|}
\hline \multirow{2}{*}{ Months } & \multicolumn{3}{|c|}{ 2011/2012 } & \multicolumn{3}{c|}{ 2012 / 2013 } \\
\cline { 2 - 7 } & Cabbage & Cauliflower & Canola & Cabbage & Cauliflower & Canola \\
\hline Sep. & 5.5 & 0 & 0.0 & 10.3 & 0.0 & 0.0 \\
\hline Oct. & 37.1 & 34.5 & 30 & 33.3 & 39.6 & 25 \\
\hline Nov. & 54.1 & 42.1 & 35 & 52.5 & 34.5 & 25.1 \\
\hline Dec. & 38.1 & 32.2 & 30.4 & 36.1 & 23.3 & 21.9 \\
\hline Jan. & 0.0 & 0.0 & 0.0 & 0.0 & 0.0 & 0.0 \\
\hline Feb. & 33.2 & 23.3 & 14 & 0.0 & 0.0 & 0.0 \\
\hline Mar. & 30 & 20 & 25.3 & 33.0 & 28.6 & 25.0 \\
\hline Apr. & 42.9 & 36.4 & 28.3 & 44.4 & 37.1 & 28 \\
\hline May & 38 & 28.9 & 16 & 43.5 & 41.7 & 18 \\
\hline Jun. & 34.9 & 28.5 & 22 & 43.5 & 43.3 & 13 \\
\hline Jul. & 31 & 23 & 20 & 40.3 & 41.2 & 20 \\
\hline Aug. & 25 & 24 & 15 & 41.6 & 30 & 0.0 \\
\hline Mean \pm SE & $30.8 \pm 0.45^{\mathrm{a}}$ & $24.4 \pm 0.28^{\mathrm{b}}$ & $19.6 \pm 0.15^{\mathrm{c}}$ & $31.5 \pm 0.85^{\mathrm{a}}$ & $26.6 \pm 0.58^{\mathrm{b}}$ & $14.7 \pm 0.14^{\mathrm{c}}$ \\
\hline
\end{tabular}

Data arranged in Table (3) showed Third parasitoid $P$. vulgaris the highest average of monthly percentage of parasitoids $P$. vulgaris during the first season2011/2012was found on cabbage(25.6\%)in June and followed by cauliflower (18.2\%)in April. and on Canola(25\%)in October 2011, while were disappeared in September, May, June and February and the lowest average percentage of parasitoids represented by $(0.01,1.5 \mathrm{and} 1.0 \%$ )on Cabbage ,Cauliflower and Canola plants, in November month respectively .

The obtained data in Table (3) showed that ,. The highest average percentage of $P$. vulgaris in the second seasons 2012/2013 recorded by 31.2 , 25 in May on cabbage and cauliflower and10.3\% on canola plants in April respectively. Meanwhile, $P$. vulgaris were disappeared in September and the lowest average of the percentage represented by 0.38 in November and 
December on cabbage and 1.5 in November on cauliflower and $1.1 \%$ in May on canola plants respectively.

As conclusion, data in Table (3) revealed that, Cabbage plants harboured the highest average percentage of $P$. vulgaris during the two successive seasons $2011 / 12$ and $2012 / 13$ and represented by $8.9 \%$ and $8.1 \%$ followed by cauliflower plants 5.8 and $6.8 \%$ while, canola plants recorded the last category and represented by $3.5 \%$ and $2.9 \%$,respectively .Moreover, there was a highly significant difference between the percentage of $P$. vulgaris on different cruciferous plants during the two successive seasons.

Table (3): The seasonal activity of the parasitoid Phryxe vulgaris parasitized pupae on different cruciferous crops during seasons 2011/12 and 2012/13

\begin{tabular}{|l|c|c|c|c|c|c|}
\hline \multirow{2}{*}{ Months } & \multicolumn{3}{|c|}{ 2011/2012 } & \multicolumn{3}{c|}{ 2012 / 2013 } \\
\cline { 2 - 7 } & Cabbage & Cauliflower & Canola & Cabbage & Cauliflower & Canola \\
\hline Sep. & 0.0 & 0.0 & 0.0 & 0.0 & 0.0 & 0.0 \\
\hline Oct. & 2.9 & 5.2 & 25 & 4.0 & 5.7 & 3.1 \\
\hline Nov. & 0.01 & 1.5 & 1.0 & 0.38 & 1.5 & 9.5 \\
\hline Dec. & 0.33 & 1.6 & 2.0 & 0.38 & 1.8 & 1.4 \\
\hline Jan. & 0.0 & 0.0 & 3.3 & 0.0 & 0.0 & 0.0 \\
\hline Feb. & 0.0 & 0.0 & 4.0 & 0.0 & 0.0 & 0.0 \\
\hline Mar. & 1 & 0.0 & 2.5 & 0.0 & 0.0 & 0.0 \\
\hline Apr. & 14.3 & 18.2 & 0.0 & 11.1 & 10.3 & 10.3 \\
\hline May & 20 & 11.1 & 0.0 & 31.2 & 25 & 1.1 \\
\hline Jun. & 25.6 & 15.4 & 0.0 & 22.0 & 19.4 & 5 \\
\hline Jul. & 17.6 & 17.4 & 4.25 & 18.18 & 17.5 & 4.25 \\
\hline Aug. & 25 & 0.0 & 0.0 & 10.5 & 0.0 & 0.0 \\
\hline Mean \pm SE & $8.9 \pm 0.29^{\mathrm{a}}$ & $5.8 \pm 0.57^{\mathrm{b}}$ & $3.5 \pm 0.05^{\mathrm{c}}$ & $8.1 \pm 0.64^{\mathrm{a}}$ & $6.8 \pm 0.32^{\mathrm{b}}$ & $2.9 \pm 0.17^{\mathrm{c}}$ \\
\hline
\end{tabular}

These results are agreement with the findings of Ragab (1992) studied the parasitoids of $P$. rapae in winter cabbage fields in season 1989/90; $P$. puparum emerged from pupa where the percentage of parasitism was $32.86 \%$. Thus, $P$. puparum was the common parasitoid recorded, its maximum percentages of parasitism $(50 \%$ and $52 \%)$ were noticed on December, $6^{\text {th }}$ and $26^{\text {th }}$ respectively , then it sharply decreased with the beginning of January. Abo-Zaid(2006)stated that, gregarious pupal ectoparasitoid, $P$. puparum occurred in the field from the middle of October to the end of January and found that the highest percentage of parasitism on pupae cabbage was $20 \%$ on the 14th of December 2004 but on the cauliflower the highest rate was 25\%on 21st December 2004. 


\section{REFFERENCES}

Abbas, M.S. (1985). Studies on the natural enemies of cabbage worm Pieris rapae L. in Egypt: Agric. Res. Rev., Cairo, 63 (1):101-107.

Abdel-Razek , A.S.; M.H. Abbas; M. El-Khouly and A. AbdelRahman (2006). Potential of microbial control of diamondback moth, Plutella xylostella L., (Lepidoptera: Plutellidae) on two cabbage cultivars under different fertilization treatments: J. Appl. Sci. Res., 2(11): 942-948.

Abo-Zaid, M.S. (2006). Biological and ecological studies on cabbage butterfly Pieris rapae L. and its natural enemies: M. Sc. Thesis, Fac. Agric., Mansoura Univ., pp 103.

Barron, M.C. (2007). Retrospective modeling indicates minimal impact of non-target parasitism by Pteromalus puparum on red admiral butterfly (Bassaris gonerilla) abundance: Biol. Control, 41(1): 53-63.

Del, M.L. ; C.I. Miles and J.A. Renwick (2005). Behavioral and chemosensory responses to a host recognition due by larvae of Pieris rapae : J. Comparative physiol.: A sensory neutral and behavioral physiology, 191(2):147-155 Duncan, B.D (1955). Multiple range and Multiple F.Test .Biometrics, 11:1-42 .

Ibrahim, A.M.;K.T.Awadallah; M.S. Abbas and M.A. Shoeb (1996). On the parasitoids of Artogeia rapae (Pieris rapae L.) . ( Egypt. J . Biol . Pest Control ) Vol. 6 (1) .

Patriche, G.(2004). Relationships between parasitoid complexes which limits the populations of Pieris brassicae L., and Pieris rapae L. (Lepidoptera: Pieridae), pests in cabbage crops from South-Eastern Rumania: Entomol. 89: 7-12, 2003-2004, ISSN $1224-2594$

Pfiffner L., Luka H., Schlatter C., Juen A .andTraugott M.( 2009) . Impact of wildflower strips on biological control of cabbage lepidopterans. Agric. Ecosyst. Environ. 129 (1-3): 310-314.

Jankowska, B. (2005). Predatory syrphids (Diptera, Syrphidae) occurring in the cabbage aphid (Brevicoryne brassica L.) colonies on different cabbage vegetables. J. Plant Prot. Res., 45(1):10-16.

Ragab, M.E. (1992). Ecological and biological studies on the parasitoids of the cabbage white butterfly, P. rapae L. (Lep.: Pieridae) in winter cabbage at Mansoura: J. Appl. Entomol., 113(5): 513-517 .

SAS INSTITUTE (1986). SAS/STAT Guide for personal Computers. Version (6 Cary, Nc, SAS institute).

Uzun, S. (1987). Parasites of the cabbage butterfly (Pieris brassicae L.) (Lepidoptera: Pieridae) harmful on cabbage and cauliflower in the Izmir district. Turkiye Entomoloji Dergisi., 11(4): 237-245. 


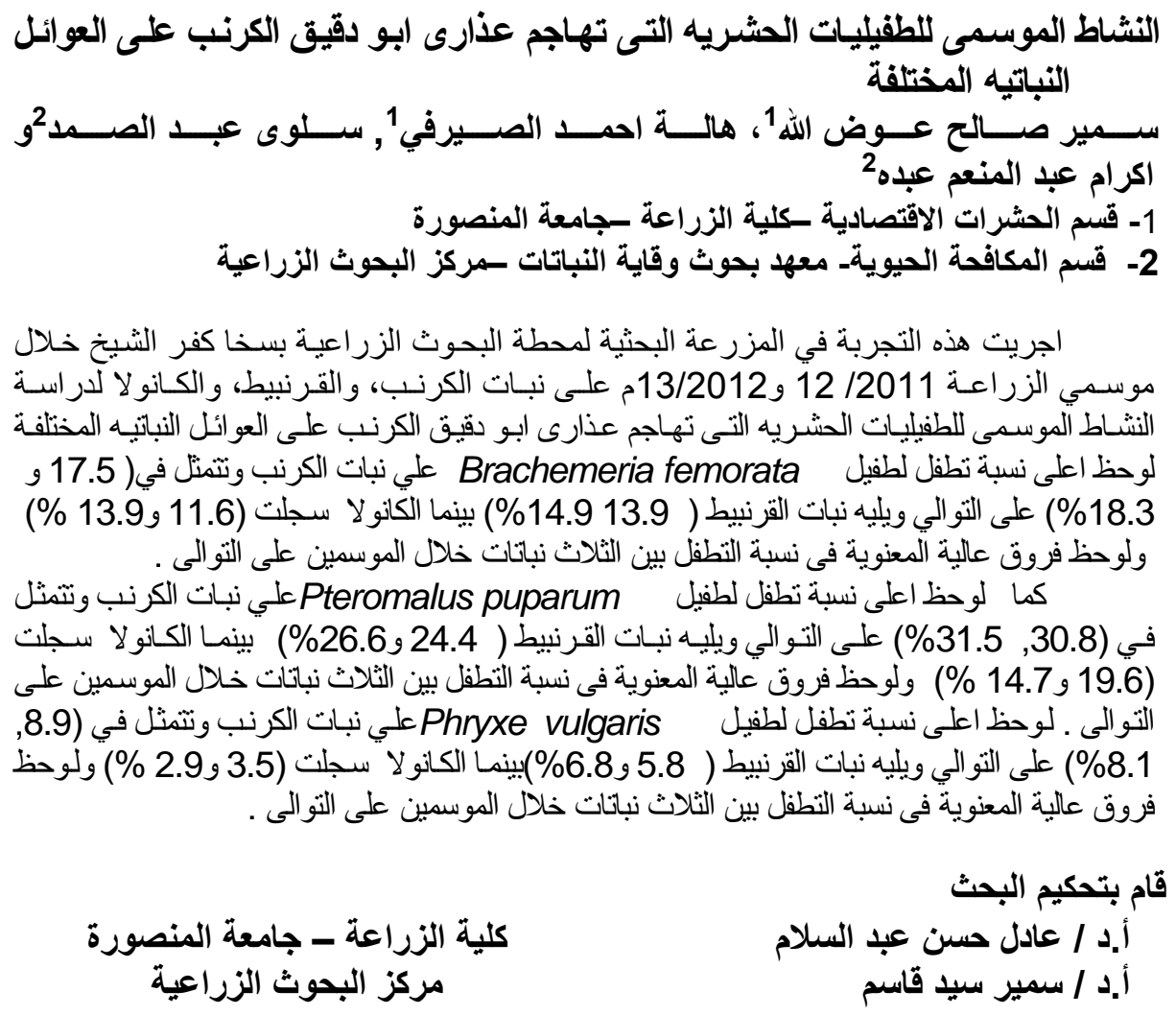

